Dunamis: Jurnal Teologi dan Pendidikan Kristiani

Volume 4, Nomor 2 (April 2020)

ISSN 2541-3937 (print), 2541-3945 (online)

http://www.sttintheos.ac.id/e-journal/index.php/dunamis

DOI: $10.30648 /$ dun.v4i2.284

\title{
Implementasi Motivasi Model ARCS (Attention, Relevance, Confidence, and Satisfaction) dalam Pembelajaran Pendidikan Agama Kristen
}

\author{
Lidia Susanti ${ }^{1}$; Carla Imbiri ${ }^{2}$ \\ STIPAK Malang ${ }^{1}$; TK CHARIS ${ }^{2}$ \\ lidiasusanti@stipakdh.ac.id
}

\begin{abstract}
The purpose of this study was to describe the effectiveness of learning using ARCS motivation in Christian Religious Education subjects $1^{\text {st }}$ grade of the elementary school. The design used in this study was a quasi experimental design and nonequivalent control group design method with 57 research subjects in $1^{\text {st }}$ grade of Charis Christian Elementary School. Learning models with ARCS motivation design as independent variables and learning outcomes as dependent variables. Through testing the difference between independent samples T-Test between the control class and the experimental class (ARCS), it was proved that there were significant differences in learning outcomes between the experimental class and the control class $t$ (57) = 4,050; $p<0.05$. Based on the results of the independent sample T-Test analysis, a significant value (Sig. $(2$ tailed $)=0.000)$ was obtained between the experimental class and the control class. From the results of this study it could be concluded that the implementation of ARCS motivation design can significantly improve learning outcomes in Christian Religious Education subjects in $1^{\text {st }}$ grade of the elementary school.
\end{abstract}

Keywords: ARCS motivation; learning strategy; Christian Religious Education; $1^{\text {st }}$ grade of the elementary school

\begin{abstract}
Abstrak
Tujuan penelitian ini untuk memberikan gambaran efektivitas pembelajaran menggunakan motivasi ARCS pada mata pelajaran Pendidikan Agama Kristen di kelas 1 SD. Rancangan penelitian ini menggunakan quasi experimental design metode nonequivalent control group design dengan subyek penelitian 57 siswa kelas 1 SD Kristen Charis. Model pembelajaran dengan desain motivasi ARCS sebagai variabel bebas dan hasil belajar sebagai variabel terikat. Melalui uji perbedaan independent samples T-Test antara kelas kontrol dan kelas eksperimen (ARCS), terbukti ada perbedaan pada hasil belajar yang signifikan antara kelompok kelas eksperimen dan kelas kontrol $\mathrm{t}(57)=4,050 ; \mathrm{p}<0.05$. Berdasarkan hasil analisa independent sample T-Test, diperoleh nilai yang signifikan (Sig. $(2$ tailed $)=0.000)$ antara kelas eksperimen dan kelas kontrol. Dari hasil penelitian ini dapat disimpulkan bahwa penerapan desain motivasi ARCS dapat secara signifikan meningkatkan hasil belajar pada mata pelajaran PAK di kelas 1 SD.
\end{abstract}

Kata Kunci: motivasi ARCS; strategi pembelajaran; Pendidikan Agama Kristen; kelas 1 SD 


\section{PENDAHULUAN}

Observasi awal yang dilakukan sebelum penelitian ini menemukan beberapa permasalahan dalam proses belajar mengajar di kelas 1 Sekolah Dasar (SD). Siswa kelas 1 SD secara umum sulit untuk berkonsentrasi dalam waktu yang cukup lama, memperhatikan penjelasan, dan memahami materi yang diberikan. Akan semakin lagi menyulitkan siswa ketika guru mengajar tanpa menggunakan media pembelajaran, metode mengajar yang variatif, dan tidak interaktif. Masalah tersebut disebabkan karena karakteristik siswa kelas 1 SD yang lebih senang bermain, suka bergerak, menyukai pekerjaan dalam kelompok, dan senang melakukan hal yang praktis, bukan teoritis. ${ }^{1}$ Kelas 1 SD adalah tahap peralihan dari Taman Kanak-kanak (TK), dari aktivitas banyak bermain, kemudian kepada aktivitas rutinitas belajar, sesuai dengan yang dikatakan oleh Santrock, "For most children, entering the first grade signal a change from being a 'homechild' to being a 'schoolchild' a situation in which new roles and obligations are experience."2 Masa peralihan tersebut menimbulkan kesulitan tersendiri bagi guru untuk menyampaikan materi pelajaran sehingga diperlukan stra-

\footnotetext{
${ }^{1}$ Erick Burhaein, "Aktivitas Fisik Olahraga Untuk Pertumbuhan Dan Perkembangan Siswa SD," Indonesian Journal of Primary Education 1, no. 1 (June 17, 2017): 51-58.
}

tegi pembelajaran yang efektif agar siswa dapat fokus kepada pemahaman materi dan tujuan pembelajaran.

Mata pelajaran Pendidikan Agama Kristen (PAK) dalam beberapa hal mengandung muatan yang abstrak, dan oleh karena itu guru perlu menjelaskan secara konkrit kepada siswa-siswinya. Hal ini juga akn menjadi kesulitan tersendiri bagi siswa kelas 1 SD karena mereka belum mampu memahami dengan baik cerita yang disampaikan, begitu pula ketika memahami maksud cerita dengan membaca Alkitab, dan menghubungkan cerita dengan hal-hal yang harus diterapkan dalam kehidupan seharihari. Kesulitan tersebut tercermin dari evaluasi hasil belajar yang diberikan, baik melalui tanya jawab maupun saat peserta didik mengerjakan soal tes tulis, juga tugas pada lembar kerja.

Untuk mencapai efektivitas dalam kegiatan belajar mengajar tidak hanya dibutuhkan strategi pembelajaran yang tepat, tetapi juga perlu dibarengi dengan stimulus yang berupa motivasi kepada siswa. Strategi pembelajaran telah direncanakan oleh guru sudah tepat tetapi belum menyentuh stimulus motivasi siswa maka proses pembelajaran akan menjadi lambat. ${ }^{3}$

\footnotetext{
2 John W Santrock, "Masa Perkembangan Anak: Children," in 2, 2011.

3 Lidia Susanti, Strategi Pembelajaran Berbasis Motivasi ARCS, ed. Amir Hamzah, 1st ed. (Malang:
} 
Menurut penelitian yang dilakukan Kurt dan Kecik, guru perlu memberikan stimulus motivasi kepada siswa sehingga dapat memunculkan minat belajar siswa, di mana motivasi siswa dapat bersifat instrinsik (dalam diri siswa) maupun ekstrinsik (dari luar diri siswa). ${ }^{4}$ Menurut Schunk, stimulus motivasi dalam kegiatan pembelajaran dapat meningkatkan minat siswa, meningkatkan usaha siswa dalam mengikuti pembelajaran, dan memberikan dorongan yang kuat dari dalam diri siswa untuk mencapai tujuan. Motivasi dapat membuat siswa berupaya untuk menggunakan kemampuannya dalam bekerja secara terus menerus dan ketika menghadapi tantangan mereka akan bertahan, bahkan mereka akan berjuang untuk memecahkan masalah. ${ }^{5}$

Adanya kendala dan kesulitan dalam pembelajaran PAK di kelas 1 SD tersebut serta melihat pentingnya stimulus motivasi mendorong peneliti untuk melakukan penelitian penggunaan motivasi model ARCS (Attention, Relevance, Confidence, and Satisfaction) sehingga mendapatkan gambaran seberapa efektif motivasi model ARCS dapat diterapak pada mata pelajaran

PT Elex Media Komputindo - Kompas Gramedia Bandung, 2019).

4 Pinar Yuncu Kurt and Ilknur Kecik, "The Effects of ARCS Motivational Model on Student Motivation to Learn English," European Journal of Foreign Languange Teaching (2017).

5 Dale H Schunk, Learning Theories: An Educational Perspective, Reading, 2012.
PAK kelas 1 SD. Dipilihnya motivasi model ARCS karena memudahkan guru dalam menggabungkan motivasi ARCS dan strategi pembelajaran sehingga menghasilkan strategi pembelajaran berbasis motivasi ARCS. Model motivasi ARCS merancang materi dan lingkungan belajar, termasuk perilaku guru sehingga peserta didik dapat merasa yakin bahwa mereka dapat mempelajari konten dan mengalami kesuksesan aktual pada suatu tugas atau tes. ${ }^{6}$

Model pembelajaran dengan desain motivasi model ARCS merupakan suatu model pembelajaran yang memungkinkan guru dengan cepat mendapatkan gambaran tentang dimensi utama motivasi siswa, terutama dalam konteks motivasi belajar intrinsik atau ekstrinsik, dan untuk menciptakan strategi yang mampu menstimulus dan mempertahankan perilaku siswa di setiap bidang pelajaran. Motivasi model ARCS juga mampu meningkatkan upaya peserta didik dan membimbing peserta didik untuk memahami konten pembelajaran. $^{7}$

Karakteristik motivasi model ARCS mewakili serangkaian kondisi yang diper-

\footnotetext{
6 "Interview with John M. Keller on Motivational Design of Instruction," Contemporary Educational Technology (2014).

${ }^{7}$ John M. Keller, Motivational Design for Learning and Performance: The ARCS Model Approach, 2010.
} 
lukan agar seseorang dapat termotivasi penuh yaitu: Perhatian (attention), berisi variabel motivasi yang berkaitan dengan upaya merangsang dan mempertahankan keingintahuan serta minat peserta didik. Relevansi (relevance), memastikan bahwa peserta didik percaya bahwa pengalaman belajar itu relevan secara pribadi, sehingga membawa peserta didik terhubung dengan lingkungannya. Relevansi dihasilkan dari menghubungkan konten pengajaran dengan tujuan pembelajaran. Kepercayaan diri (confidence), merupakan kondisi dimana peserta didik yakin untuk dapat mencapai kesuksesan sama dengan teman-teman yang lain. Rasa puas (satisfaction), peserta didik harus memiliki perasaan puas dengan proses pembelajaran dan hasil belajarnya. Kepuasan ini mengacu pada perasaan positif tentang prestasi dan pengalaman belajar seseorang. Siswa yang menerima pengakuan dan bukti keberhasilan akan mendukung pembelajaran berikutnya karena perasaan puas tersebut timbul dari dalam diri mereka sendiri (intrinsik). Imbalan ekstrinsik yang nyata juga dapat menghasilkan kepuasan, dan bisa juga berupa mengintegrasikan motivasi substantif atau simbolis.
Penelitian terdahulu tentang penerapan motivasi model ARCS menyatakan bahwa penerapan motivasi model ARCS menolong pembelajaran Bahasa Inggris dengan hasil yang sangat signifikan sehingga pembelajaran dapat disampaikan dengan efektif, hasil belajar meningkat, dan peserta didik memiliki motivasi selama pembelajaran berlangsung. ${ }^{8}$ Menurut Keller, motivasi model ARCS mampu menciptakan strategi pembelajaran yang dapat merangsang dan mempertahankan perhatian peserta didik dalam proses pembelajaran di setiap bidang studi. Selain itu motivasi ARCS dapat meningkatkan upaya peserta didik dan membimbing peserta didik untuk memahami konten dan metode pembelajaran. ${ }^{9}$

\section{METODE PENELITIAN}

Penelitian ini menggunakan pendekatan kuantitatif. Jenis penelitian ini adalah penelitian desain Quasi Experimental. Jenis desain Quasi Experiment yang digunakan dalam penelitian ini adalah Nonequivalent Control-Group Design. Peneliti menggunakan kelompok utuh karena tidak memungkinkan mengubah jumlah siswa yang ada di dalam kelas. Berikut merupakan gambar

\footnotetext{
9 Keller, Motivational Design for Learning and

Performance: The ARCS Model Approach.
}

8 Kurt and Kecik, "The Effects of ARCS Motivational Model on Student Motivation to Learn English." 
quasi experimental design metode 2 Relevance

$6,9,10,16, \quad 9$ nonequivalent control group design: ${ }^{10}$

\begin{tabular}{|lll}
\hline $\mathrm{O}_{1}$ & $\mathrm{X}$ & $\mathrm{O}_{2}$ \\
\hline $\mathrm{O}_{3}$ & & $\mathrm{O}_{4}$
\end{tabular}

Gambar 1. Desain nonequivalent control group

Keterangan:

$$
\begin{aligned}
\mathrm{O} 1= & \begin{array}{l}
\text { Kelompok eksperimen sebelum } \\
\text { diberi perlakuan }
\end{array} \\
02= & \begin{array}{l}
\text { Kelompok ekperimen setelah } \\
\text { diberi perlakuan }
\end{array} \\
03= & \begin{array}{l}
\text { Kelompok kontrol sebelum } \\
\text { diberi perlakuan }
\end{array} \\
04= & \begin{array}{l}
\text { Kelompok kontrol yang tidak } \\
\text { diberi perlakuan }
\end{array} \\
\mathrm{X}= & \begin{array}{l}
\text { Perlakuan } \\
\text { motivasi ARCS }
\end{array}
\end{aligned}
$$

Kelompok eksperimen dan kontrol diberikan pretest dan postest.

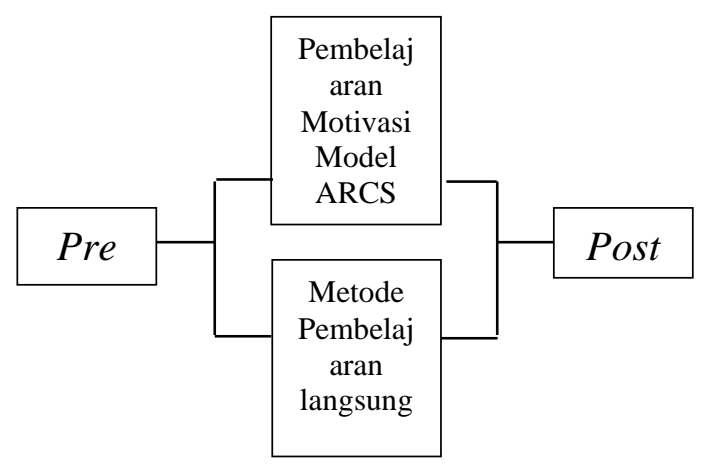

Gambar 2. Prosedur pretest \& posttest

\begin{tabular}{lllc}
\hline N o & Indikator & Nomor Butir & $\begin{array}{c}\text { Jumlah } \\
\text { Butir }\end{array}$ \\
\hline 1 & Attention & $2,8,11,12^{*}$, & 12 \\
& & $15^{*}, 17,20$, & \\
& & $22^{*}, 24,28$, & \\
& & $29 *, 31 *$
\end{tabular}

10 Sugiyono, "Metode Penelitian Pendidikan Pendekatan Kuantitaif, Kualitatif, Dan R\&D," Metode Penelitian Pendidikan Pendekatan Kuantitaif, Kualitatif, Dan R\&D, 2013. Bruce W.
$18,23,26^{*}$, 30,33

3 Confidence

$1,3^{*}, 4,7,13$, $19 *, 25,34 *$, 35

4 Satisfaction $5,14,21,27, \quad 6$ 32,36

Jumlah 36

Tabel 1. Kisi-kisi angket ARCS ${ }^{11}$

Keterangan: Tanda * untuk pernyataan negatif

Pada penelitian ini, variabel bebas (X) adalah strategi pembelajaran, menggunakan dua kelas, yaitu (X1) kelas eksperimen, kelas yang menggunakan strategi pembelajaran dengan modifikasi motivasi model ARCS; (X2) kelas kontrol (menggunakan strategi pembelajaran langsung), dan variabel terikat $(\mathrm{Y})$ adalah hasil belajar PAK. Penelitian dilaksanakan di kelas 1 SD Charis Malang. Jumlah peserta didik yang mengikuti pembelajaran dengan motivasi model ARCS 37 anak, sedangkan yang mengikuti pembelajaran langsung 20 anak, total peserta didik ada 57 anak.

Tuckman, "Conducting Educational Research," Conducting Educational Research (1999).

11 Keller, Motivational Design for Learning and Performance: The ARCS Model Approach. 
Sintaks motivasi ARCS $^{12}$ yang digunakan dalam penelitian ini sebagai berikut: 1) Dapatkan informasi tentang kelas /sekolah; 2) Dapatkan informasi tentang peserta didik; 3) Menganalisis peserta didik; 4) Menganalisis materi yang ada; 5) Membuat daftar tujuan dan evaluasi penilaian; 6) Membuat daftar strategi pembelajaran; 7) Memilih desain pembelajaran yang akan dipakai; 8) Mengintegrasi desain dalam pembelajaran; 9) Memilih dan mengembangkan materi belajar; 10) Mengevaluasi dan merevisi.

\section{HASIL DAN PEMBAHASAN}

Validasi dan reliabilitas angket ARCS terdapat pada Tabel 4, yang terlihat bahwa angket yang digunakan adalah valid dan signifikan, dihitung dengan SPSS versi $23^{13}$.

\begin{tabular}{cc}
\hline Scale & $\begin{array}{c}\text { Validitas } \\
\text { \&Reliability } \\
\text { (Cronbach Alpha) }\end{array}$ \\
\hline Attention & 0.89 \\
Relevance & 0.81 \\
Confidence & 0.90 \\
Satisfaction & 0.92 \\
Total Scale & 0.96 \\
\hline
\end{tabular}

Tabel 2. Validitas \& Reliabiliabilitas

Angket motivasi model ARCS yang digunakan valid dan reliabel terlihat dari

12 Ibid.
Tabel 2, yang memiliki Alpha Cronbach di atas 0.6, sehingga angket tersebut dapat digunakan dalam penelitian ini.

\section{Deskripsi Pretest Hasil Belajar}

Data hasil pretest siswa yang diajar menggunakan strategi pembelajaran Motivasi ARCS dan pembelajaran langsung terlihat ada perbedaan, digambarkan pada grafik berikut:

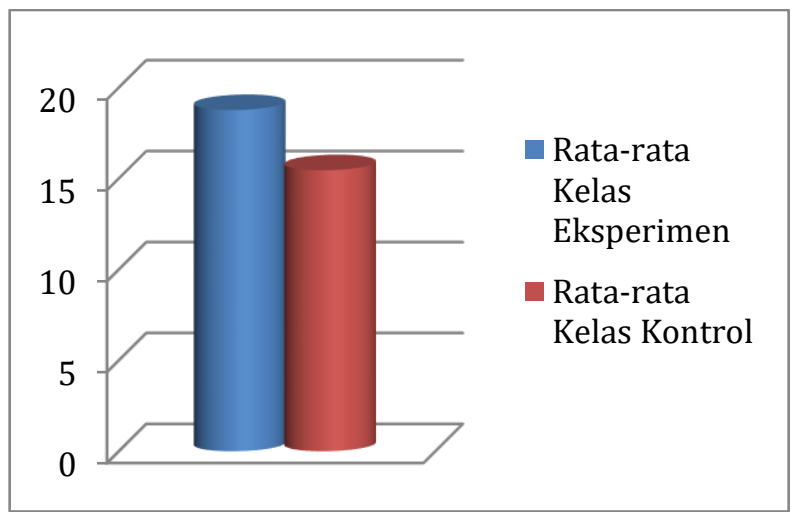

Gambar 3. Pre test hasil belajar PAK

Hasil pemberian pretest di awal pembelajaran pada siswa kelas 1 SD Charis, Gambar 3, menunjukkan hanya sedikit perbedaan nilai antara kelas kontrol (strategi pembelajaran langsung yang tidak menggunakan motivasi model ARCS) dan kelas eksperimen (menggunakan strategi pembelajaran yang dimodifikasi dengan motivasi model ARCS).

\section{Deskripsi Post test Hasil Belajar}

Data hasil post test siswa yang diajar menggunakan strategi pembelajaran

13 V. Wiratna Sujarweni, "SPSS Untuk Penelitian," in SPSS Untuk Penelitian, 2015. 
Motivasi ARCS dan pembelajaran langsung terdapat perbedaan, digambarkan pada grafik berikut:

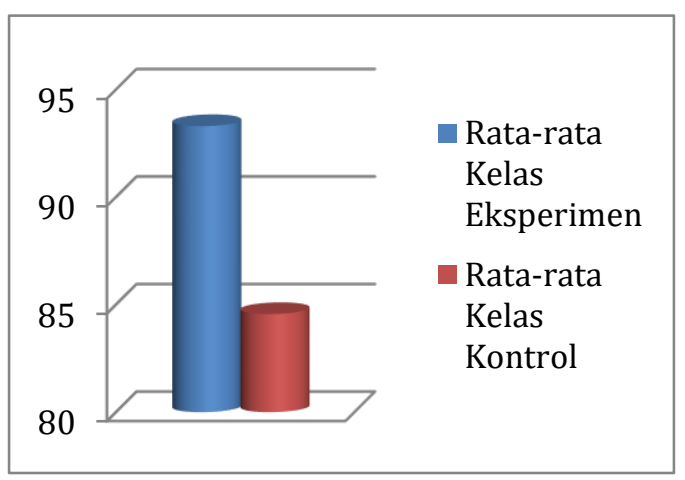

Gambar 4. Post Test Hasil Belajar PAK

Gambar 4 memperlihatkan perbedaan yang signifikan pada hasil post test antara kelas yang dibelajarkan menggunakan motivasi model ARCS dan kelas kontrol (yang menggunakan pembelajaran langsung/ yang tidak menggunakan motivasi model ARCS). Data tersebut menunjukkan bahwa pembelajaran yang menggunakan motivasi model ARCS akan memberikan stimulus kepada peserta didik dalam mengikuti kegiatan proses belajar dan mengikuti evaluasi hasil belajar (post test) yang diberikan oleh guru.

Data hasil post test kemudian dilakukan analisis dengan uji Independent Sample T-test. Tujuan analisis statistik ini adalah untuk mengetahui tingkat kesetaraan kedua kelompok perlakuan strategi pembe-

14 T Gök and I Sýlay, "The Effects of Problem Solving Strategies on Students' Achievement, lajaran tersebut. Berikut ini disajikan data statistik kelompok uji t post test:

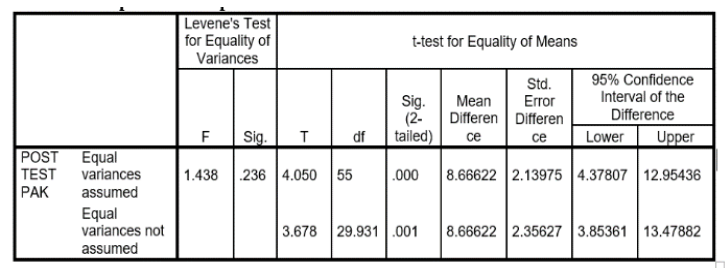

Tabel 3. Independent sampel T-test Post Test

Uji Normalitas memiliki nilai signifikan 0.00 yang menunjukkan data tersebar secara normal. Berdasarkan hasil uji statistic Independent Sample T-test dengan bantuan program SPSS 23.0 menggunakan taraf signifikansi 5\%. Hasil Levene Test F (57) $=$ Sig. $0.236>0.05$ artinya data kedua kelompok dianggap homogen secara variansnya. Nilai signifikan untuk post test atau hasil belajar PAK antara kelompok strategi pembelajaran dengan desain motivasi ARCS dan kelompok strategi pembelajaran langsung dengan Sig. (2-tailed) adalah angka yang menunjukkan sebesar 0,000 $<0.05(\mathrm{p}<0.05)$, artinya ada perbedaan yang signifikan hasil belajar PAK (post test) antara kelas yang menggunakan strategi pembelajaran dengan motivasi ARCS dan kelas yang menggunakan strategi pembelajaran langsung. Hasil tersebut membuktikan bahwa penggunaan strategi pembelajaran yang tepat berpengaruh besar pada hasil belajar siswa. ${ }^{14}$

Attitude and Motivation," Latin-American Journal of Physics Education (2010). Adebola Ifamuyiwa, 
Berdasarkan paparan di atas, hasil analisis data menunjukkan bahwa dalam penelitian ini:

1. Ada perbedaan skor nilai pretest dan posttest antara kelompok siswa yang dibelajarkan menggunakan strategi pembelajaran dengan modifikasi motivasi model ARCS dan kelompok siswa yang dibelajarkan menggunakan strategi pembelajaran langsung.

2. Ada skor peningkatan nilai yang signifikan dari hasil postest yang diberikan kepada kelompok siswa yang dibelajarkan menggunakan strategi pembelajaran modifikasi motivasi model ARCS dan kelompok siswa yang dibelajarkan menggunakan strategi pembelajaran langsung.

\section{Pembahasan Hasil Penelitian}

Hasil penelitian yang dilakukan menunjukkan bahwa motivasi model ARCS dapat digunakan di dalam kelas dengan menggabungkan strategi pembelajaran yang telah ditentukan oleh guru sehingga dalam proses pembelajaran peserta didik menerima stimulus motivasi, yang dapat memberikan dorongan dan peserta didik akan bekerja keras untuk

"The Effect of Behavioural Objectives on Students' Achievement in Senior Secondary School Mathematics Instructions When Used as Advance Organizers," American Journal of Scientific and Industrial Research (2011). mencapai tujuan yang diinginkan. Motivasi model ARCS dapat dimodifikasi dengan strategi pembelajaran sehingga dalam proses pembelajaran akan memungkinkan guru untuk dengan cepat mendapatkan gambaran tentang dimensi utama motivasi siswa dalam belajar, terutama dalam konteks motivasi intrinsik dan ekstrinsik siswa, sehingga dapat menciptakan strategi pembelajaran yang tepat, dapat menstimulus dan mempertahankan perilaku peserta didik di setiap proses pembelajaran.

Hasil penelitian ini selaras dengan pendapat Colakoglu dan Akdemir, bahwa pembelajaran yang dikembangkan dengan motivasi model ARCS dapat meningkatkan perhatian peserta didik selama pembelajaran, sehingga mampu mengembangkan relevansi kebutuhan peserta didik dan dapat membuat harapan positif peserta didik untuk mencapai sukses serta memiliki rasa puas dalam menggapai keberhasilannya. ${ }^{15}$ Sedangkan menurut pendapat Keller, adanya motivasi model ARCS dalam pembelajaran dapat meningkatkan upaya peserta didik, serta membimbing peserta didik untuk memahami konten dan materi

15 Ozgur M. Colakoglu and Omur Akdemir, "Motivational Measure of the Instruction Compared: Instruction Based on the ARCS Motivation Theory V.S. Traditional Instruction in Blended Courses," Turkish Online Journal of Distance Education (2010). 
pembelajaran. ${ }^{16}$ Ini berarti bahwa pembelajaran dengan motivasi model ARCS dapat meningkatkan daya tarik atau minat peserta didik sehingga mampu menstimulasi peningkatan upaya peserta didik dalam menyelesaikan dan menerapkan hasil didikan.

Apabila guru menggunakan motivasi model ARCS dalam proses pembelajaran, maka fokus seorang guru tertuju pada empat hal, yaitu: perhatian siswa (attention), pembelajaran yang relevan (relevance), menstimulus percaya diri siswa (confidence), dan kepuasan siswa dalam mencapai keberhasilan (satisfaction) sehingga akan didapatkan proses pembelajaran yang mampu menstimulus peserta didik untuk belajar dan hasil belajar peserta didik akan mengalami peningkatan. Selanjutnya, agar mereka memiliki keinginan untuk terus belajar, mereka harus memiliki perasaan ingin tahu dalam proses belajar dan mereka perlu memiliki rasa puas dalam usahanya untuk belajar. Ini sesuai dengan pendapat Chang dkk, bahwa pembelajaran yang dikembangkan atas dasar ARCS dapat meningkatkan perhatian peserta didik selama pembelajaran. ${ }^{17}$ Namun demikian, guru juga perlu mengembangkan relevansi materi yang diajarkan sehingga ada hubungan antara teori dan kebutuhan

16 "Interview with John M. Keller on Motivational Design of Instruction." keingintahuan peserta didik. menimbulkan rasa percaya diri peserta didik, membuat harapan positif untuk sukses, dan memiliki kepuasan dalam keberhasilan.

\section{KESIMPULAN}

Implementasi motivasi model ARCS memberikan hasil yang signifikan pada proses pembelajaran PAK di kelas 1 SD. Motivasi model ARCS mampu mengatasi hambatan kesulitan berkonsentrasi dalam waktu yang lama dan pemahaman terhadap materi pembelajaran yang sifatnya abstrak.

\section{UCAPAN TERIMA KASIH}

Penulis menyampaikan penghargaan dan ucapan terima kasih kepada Carla Imbiri atas kontribusinya dalam melaksanakan penelitian bersama dengan penulis.

\section{DAFTAR PUSTAKA}

Burhaein, Erick. “Aktivitas Fisik Olahraga Untuk Pertumbuhan Dan Perkembangan Siswa SD." Indonesian Journal of Primary Education 1, no. 1 (June 17, 2017): 51.

Chang, Ching, Chih Kai Chang, and Ju Ling Shih. "Motivational Strategies in a Mobile Inquiry-Based Language Learning Setting." System (2016).

Colakoglu, Ozgur M., and Omur Akdemir. "Motivational Measure of the Instruction Compared: Instruction Based on the ARCS Motivation Theory V.S. Traditional Instruction in

${ }^{17}$ Ching Chang, Chih Kai Chang, and Ju Ling Shih, "Motivational Strategies in a Mobile Inquiry-Based Language Learning Setting," System (2016). 
Blended Courses." Turkish Online Journal of Distance Education (2010).

Gök, T, and I Sýlay. "The Effects of Problem Solving Strategies on Students' Achievement, Attitude and Motivation." Latin-American Journal of Physics Education (2010).

Ifamuyiwa, Adebola. "The Effect of Behavioural Objectives on Students' Achievement in Senior Secondary School Mathematics Instructions When Used as Advance Organizers." American Journal of Scientific and Industrial Research (2011).

Keller, John M. Motivational Design for Learning and Performance: The ARCS Model Approach. 2010.

Kurt, Pinar Yuncu, and Ilknur Kecik. "The Effects of ARCS Motivational Model on Student Motivation to Learn English." European Journal of Foreign Languange Teaching (2017).

Santrock, John W. "Masa Perkembangan Anak: Children.” In 2, 2011.
Schunk, Dale H. Learning Theories: An Educational Perspective. Reading, 2012.

Sugiyono. "Metode Penelitian Pendidikan Pendekatan Kuantitaif, Kualitatif, Dan R\&D." Metode Penelitian Pendidikan Pendekatan Kuantitaif, Kualitatif, Dan $R \& D, 2013$.

Sujarweni, V. Wiratna. "SPSS Untuk Penelitian.” In SPSS Untuk Penelitian, 2015.

Susanti, Lidia. Starategi Pembelajaran Berbasis Motivasi ARCS. Edited by Amir Hamzah. 1st ed. Malang: PT Elex Media Komputindo - Kompas Gramedia Bandung, 2019.

Tuckman, Bruce W. "Conducting Educational Research." Conducting Educational Research (1999).

"Interview with John M. Keller on Motivational Design of Instruction." Contemporary Educational Technology (2014). 